\title{
Correction to: A probabilistic approach to student workload: empirical distributions and ECTS
}

\author{
Antonio Souto-Iglesias $^{1}$ (D) $\cdot$ María Teresa Baeza_Romero $^{2}$ (D)
}

Published online: 23 May 2018

(C) Springer Science+Business Media B.V., part of Springer Nature 2018

\section{Correction to: High Educ}

$$
\text { https://doi.org/10.1007/s10734-018-0244-3 }
$$

The original version of this article unfortunately contained a mistake. The name "Antonio Souto-Inglesias" should be corrected to "Antonio Souto-Iglesias".

The original article has been corrected.

The online version of the original article can be found at https://doi.org/10.1007/s10734-018-0244-3

María Teresa Baeza_Romero

mariateresa.baeza@uclm.es

Antonio Souto-Iglesias

antonio.souto@upm.es

1 CEHINAV, DMFPA, ETSIN, Universidad Politécnica de Madrid (UPM), Madrid, Spain

2 Escuela de Ingeniería Industrial de Toledo, Avenida Carlos III s/n Real Fábrica de Armas, 45071 Toledo, Spain 